\title{
Morphological Characteristics of Human Extrahepatic Bile Duct Carcinoma
}

\author{
Toshiyuki SakUma ${ }^{1,2}$, Hiroshi KIJMA ${ }^{1}$, Hiroyuki Kashiwagl ${ }^{3}$, Shoichi Dowaki ${ }^{3}$, Yasuo OhtanI, Toshihide \\ Imaizumi ${ }^{3}$, Hiroyasu MakuUChI', Hidenobu Watanabe", Hitoshi Yamazaki', Masato Nakamura', Yoshito \\ UEYAMA ${ }^{1}$ and Tetsuya Mine' ${ }^{2}$ \\ ${ }^{1}$ Departments of Pathology, ${ }^{2}$ Gastroenterology, and ${ }^{3}$ Surgery, Tokai University School of Medicine, Isehara, Kanagawa 259-1193, Japan; \\ and ${ }^{4}$ Department of Pathology, Niigata University School of Medicine, Niigata 951-8510, Japan
}

(Received 18 September 2003; and accepted 9 October 2003)

\begin{abstract}
The number of surgically resected cases of extrahepatic bile duct cancers has been increased because of the recent advances in imaging diagnoses and operative procedures. However, morphological characteristics of the extrahepatic bile duct cancers have not yet been defined. In this study, we reviewed 102 surgically resected cancer cases for clarifying growth and invasion of the extrahepatic bile duct cancer. We designated as "early cancer" cancers limited to the mucosa or invading as far as the fibromuscular layer (smooth muscle layer), i.e., Tis or T1 cancers. Approximately $12.7 \%(13 / 102)$ of the cases were pTis or pT1 cancers (pathologic stage of Tis or T1), which were categorized as early cancer. Only $15.4 \%(2 / 13)$ of the early cancers showed vascular/perineural invasion and/or lymph node metastasis. In contrast, the majority $(87.3 \%)$ of the cases was pT2-3 cancers, and very frequently showed vascular/perineural invasion and/or lymph node metastasis. Desmin immunostaining was very useful for recognizing thin muscle layer, and should be performed for pathological diagnosis of early extrahepatic bile duct cancers.
\end{abstract}

Bile duct cancer is one of the most important lesions of extrahepatic bile duct, and is the third most common cause of bile duct obstruction $(1,2)$. Extrahepatic bile duct cancers are most frequently detected in the sixth or seventh decades of age. Patients with extrahepatic bile duct cancer are usually treated at an advanced stage, showed obstructive jaundice, and the prognosis remains poor despite the development of modern diagnostic methods $(9,10,30)$. Hepatic metastasis is the most common form of progression of extrahepatic bile duct cancer. Microscopically, the majority of extrahepatic bile duct cancers are adenocarcinoma with various differentiations $(1,2$, 30 ). Many adenocarcinomas show moderate to poor

Correspondence to: Dr. Hiroshi Kijima, Department of Pathology, Tokai University School of Medicine, Bohseidai, Isehara, Kanagawa 259-1193, Japan

Tel: +81-463-93-1121, Fax: +81-463-91-1370

e-mail: hkijima@is.icc.u-tokai.ac.jp differentiation with a nodular or flat surface, but they may also be deeply invasive, associated with desmoplastic stromal reaction. Previously, we clinicopathologically examined a number of surgically resected gallbladder cancers including early-stage carcinomas, and analyzed their histogenesis and tumor growth, but did not analyze the clinicopathological findings of bile duct cancers $(8,16,17,19,20$, 26).

Immunostaining (immunohistochemical staining) is useful for characterization of cell phenotypes. Several antibodies, such as desmin, myoglobin and actin, are used as immunohistochemical muscle markers. Desmin is a $53-\mathrm{kDa}$ intermediate filament protein in muscle cells, i.e, both skeletal and smooth muscle cells $(3,23,24,34)$. The immunoreactivity of desmin was suggested to be specific for muscle cells and myogenic tumors. In contrast, alpha-smooth muscle actin ( $\alpha$-SMA) has been detected in smooth muscles, myofibroblasts and fibro- 
blasts $(22,27)$. Immunostaining against $\alpha$-SMA demonstrates histological and/or cytological localization of not only the smooth muscle, but also myofibroblastic and myoepithelial cells of human organs.

In the present study, we reviewed surgically resected cases of human extrahepatic bile duct cancers, and analyzed their morphological characteristics. In addition, we performed immunostaining against desmin and $\alpha$-SMA in order to recognize the thin muscle layer proper of the bile duct, and to evaluate the invasion/depth of the bile duct cancer.

\section{MATERIALS AND METHODS}

Extrahepatic bile duct carcinoma tissue specimens. All tissue specimens were obtained from surgical resections of extrahepatic bile duct cancers at our university hospitals. One hundred and two patients with extrahepatic bile duct cancers were included in this study (76 males and 26 females), and subjects ranged in age from 41 to 84 years old (mean, 67.0). Stages of extrahepatic bile duct cancer were classified according to the TNM classification, which specifies the following tumor characteristics (T: Primary Tumor, N: Regional Lymph Nodes, M: Distant Metastasis) (29). Gross type of cancer was classified into three groups, i.e., papillary type, nodular type and diffusely infiltrating type. We designated as "early cancer" cancers limited to the mucosa or invading as far as the fibromuscular layer (smooth muscle layer), i.e., Tis or T1 cancers.

Histological Examination. Extrahepatic bile duct tissue specimens were rapidly fixed in $10 \%$ buffered formalin for $2448 \mathrm{~h}$ for histological and immunohistochemical analyses. All of the resected extrahepatic bile ducts bearing the carcinomas were cut serially into $5-\mathrm{mm}$ tissue blocks, and routinely embedded in paraffin. Histological analyses including tumor invasion were examined on 4- $\mu$ m-thick sections stained with hematoxylin and eosin. The degree of stromal tumor invasion was classified into three groups, i.e., medullary growth pattern, intermediate growth pattern and scirrhous growth pattern. The degree of venous invasion was classified into four groups as follows: v0, no venous invasion; v1+, minimal venous invasion, i.e., one or two foci of venous invasion in histological sections; v2+, moderate venous invasion, i.e., three or four foci; and v $3+$, severe venous invasion with greater than five foci. The degree of lymphatic invasion was classified as follows: ly0, no lymphatic invasion; ly $1+$, mild lymphatic invasion; ly $2+$, moderate lymphatic invasion; and ly $3+$, severe lymphatic invasion. The degree of perineural invasion was classified as follows: pno, no perineural invasion; pn1t, mild perineural invasion; pn2t, moderate perineural invasion; and pn3+, severe perineural invasion.

Immunohistochemical analysis. Immunohistochemical staining was performed using the Labeled Streptavidin-Biotin (LSAB) method with our modifications $(4,33)$. Sections $(4 \mu \mathrm{m})$ cut from paraffinembedded tissues were deparaffinized, and endogenous peroxidase activity was quenched by incubation in $0.3 \% \quad \mathrm{H}_{2} \mathrm{O}_{2}$ in methanol for $30 \mathrm{~min}$. Nonspecific binding was blocked with normal sheep serum in $0.1 \%$ trypsin solution in $\mathrm{CaCl}_{2} /$ phosphatebuffered saline (PBS), and then slides were incubated with mouse monoclonal antibodies against human desmin (1:200 in dilution) (D33; DAKO, Glostrup, Denmark) or $\alpha$-SMA $(1: 400)$ (1A4; Sigma, St. Louis, MO), for one hour at room temperature. Slides were subsequently incubated with biotinylated anti-mouse $\operatorname{Ig}$ (Fab) 2 antibody (1 : 100) (Amersham International plc., Buckinghamshire, UK) for $60 \mathrm{~min}$, and immunoreactivity was detected using horseradish peroxidase-conjugated streptavidin.

Statistical analysis. The $\chi^{2}$ test and Yates' correction were used for comparisons between group frequencies.

\section{RESULTS}

Gross findings of extrahepatic bile duct cancer are represented in Fig. 1 and summarized in Table 1. We evaluated the depth of invasion of the bile duct cancers, using immunohistochemical staining for desinin and $\alpha$-SMA (Fig. 2). The thin fibromuscular layer (smooth muscle layer, proper muscle layer) of the extrahepatic bile duct was easily recognized, using desmin staining rather than $\alpha$-SMA staining. Desmin immunoreactivity was detected at the fibromuscular layer, while $\alpha$-SMA immunoreactivity was found at the fibromuscular layer, as well as at the fibroblasts and vascular walls. Thirteen $(12.7 \%)$ of 102 carcinomas were limited within the proper muscle layer (Tis or $\mathrm{T} 1$ cancers, i.e., early cancers), and $89(87.3 \%)$ carcinomas invaded the subserosa (T2 or T3, i.e., T2-3 cancers). All the Tis and T1 cancers (13 tumors) were grossly papillary type, while $86.5 \%(77 / 89)$ of T2-3 cancers were nodular or diffusely infiltrating type (Figs. 3 and 4). The majority of diffusely infiltrating tumors showed scirrhous 

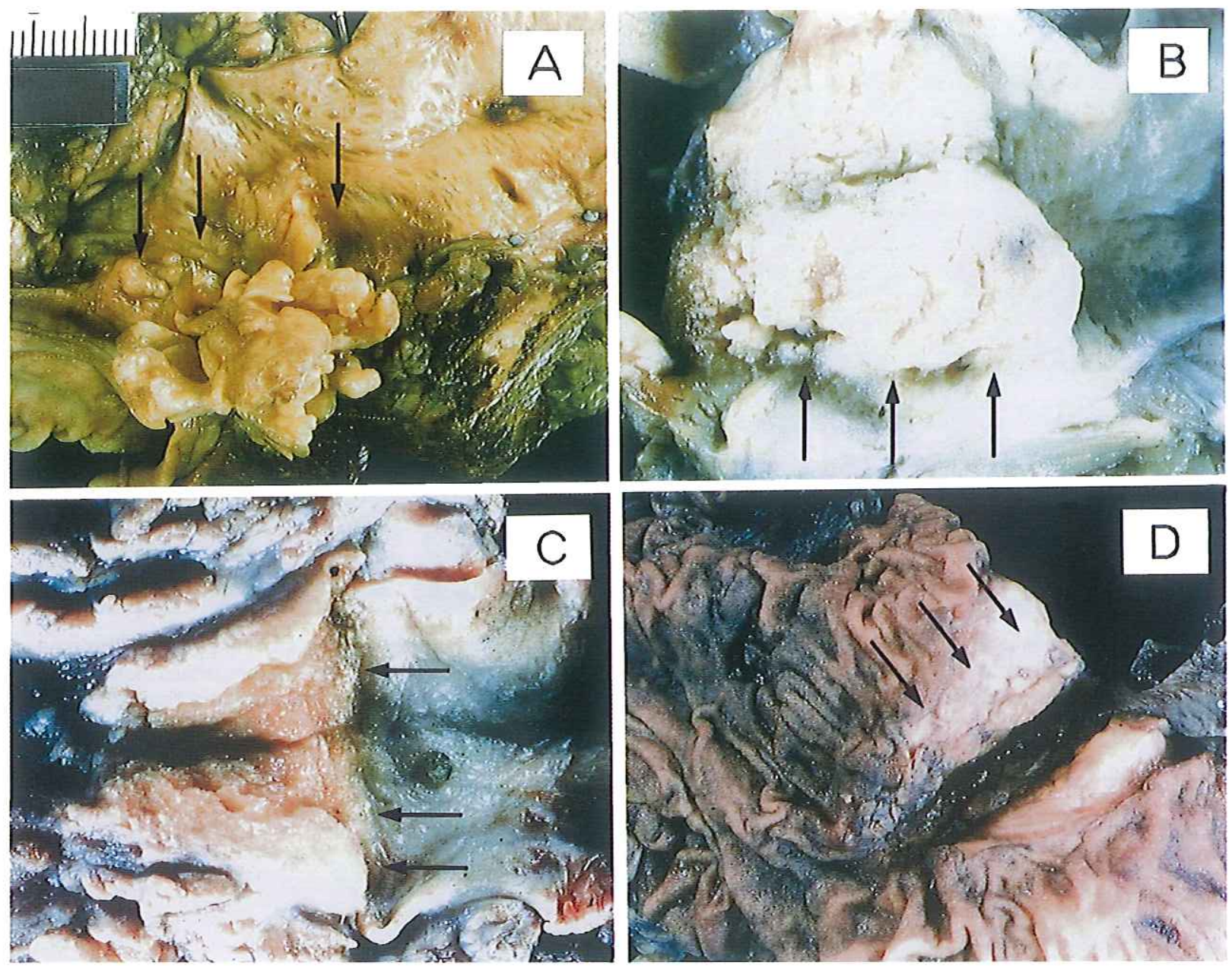

Fig. 1 Gross findings of extrahepatic bile duct cancers. An early cancer, papillary type, is located to the mucosa of extrahepatic bile duct $(A$, arrows). Advanced cancers, papillary type $(B$, arrows), nodular type ( $C$, arrows) and diffusely infiltrating type (D, arrows), invade the walls of extrahepatic bile duct.

Table 1 Morphological findings of extrahepatic bile duct cancer

\begin{tabular}{lrr}
\hline $\begin{array}{l}\text { Extrahepatic bile duct cancer } \\
\text { Primary tumor } \\
\text { pTis and pT1 }\end{array}$ & $(\mathrm{n}=102)$ \\
Papillary type & 13 & \\
pT2 and pT3 & $12.7 \%)$ \\
Papillary type & 45 & $(11.8 \%)$ \\
Nodular type & 32 & $(31.4 \%)$ \\
Diffusely infiltrating type & & \\
& 4 & \\
Location of extrahepatic bile duct cancer & 19 & \\
Hepatic hilum & 33 & \\
Upper third of extrahepatic bile duct & 46 & \\
Middle third of extrahepatic bile duct & & \\
Lower third of extrahepatic bile duct & 5 & $(4.9 \%)$ \\
Histological type of extrahepatic bile duct cancer & 31 & $(30.4 \%)$ \\
Papillary adenocarcinoma & 35 & $(34.3 \%)$ \\
Well differentiated adenocarcinoma & 28 & $(27.5 \%)$ \\
Moderately differentiated adenocarcinoma & 1 & $(1.0 \%)$ \\
Poorly differentiated adenocarcinoma & 1 & $(1.0 \%)$ \\
Mucinous adenocarcinoma & 1 & $(1.0 \%)$ \\
Adenosquamous carcinoma & & \\
Undifferentiated carcinoma & & \\
\end{tabular}



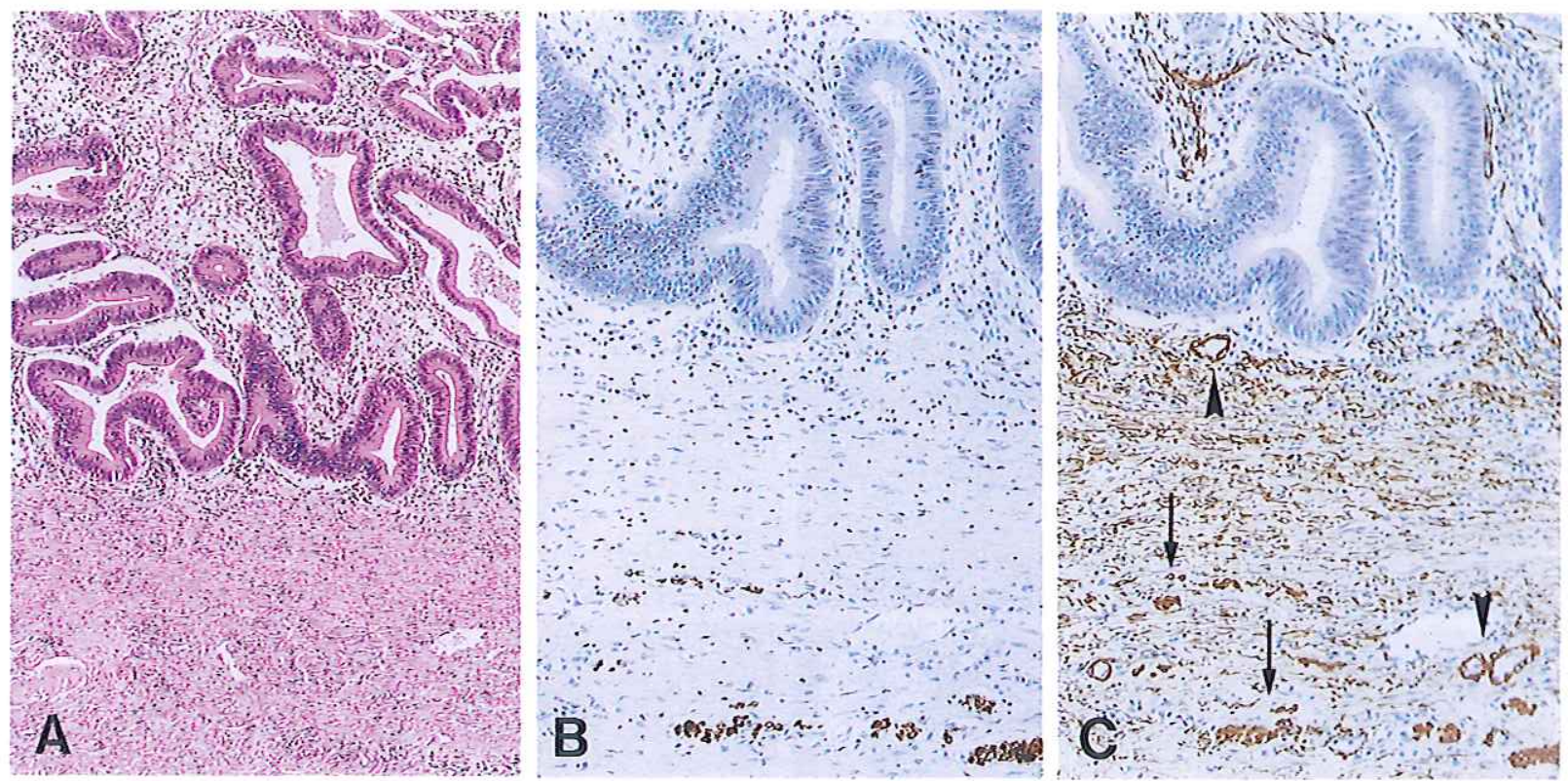

Fig. 2 Microscopic findings of extrahepatic bile duct adenocarcinoma. Adenocarcinoma cells are limited to the bile duct mucosa $(A$, hematoxylin and eosin, $\times 40)$. Desmin immunoreactivity was detected at the thin fibromuscular layer (B, LSAB method, $\times 80$ ). Alpha smooth muscle actin was found at the fibromuscular layer (arrows), as well as at the fibroblasts and vascular walls (arrowheads) (C, LSAB method, $\times 80)$.
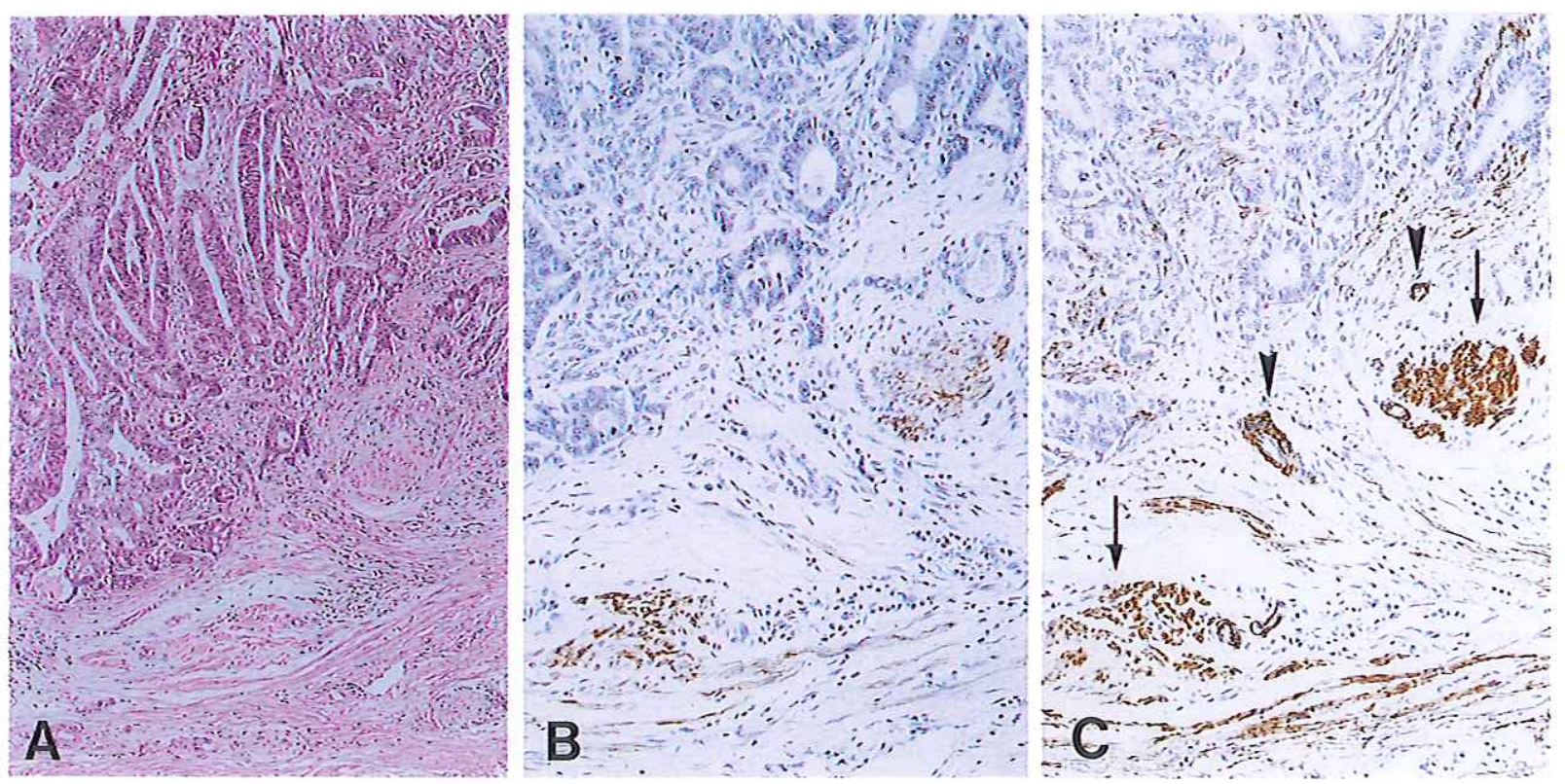

Fig. 3 Microscopic findings of extrahepatic bile duct adenocarcinoma. Adenocarcinoma cells invade the fibromuscular layer $(A$, hematoxylin and eosin, $\times 40)$. Desmin immunoreactivity was detected at the thin fibromuscular layer (B, LSAB method, $\times$ 80). Alpha smooth muscle actin was found at the fibromuscular layer (arrows), as well as at the fibroblasts and vascular walls (arrowheads) $(C$, LSAB method, $\times 80)$.

stromal invasion, while forty-five (44.1\%) of 102 carcinomas exhibited scirrhous invasion (Table 2). Histologically, $69.6 \%(71 / 102)$ of the bile duct can- cers were composed of differentiated adenocarcinoma (Table 1).

Vascular/perineural invasion and lymph nodal me- 

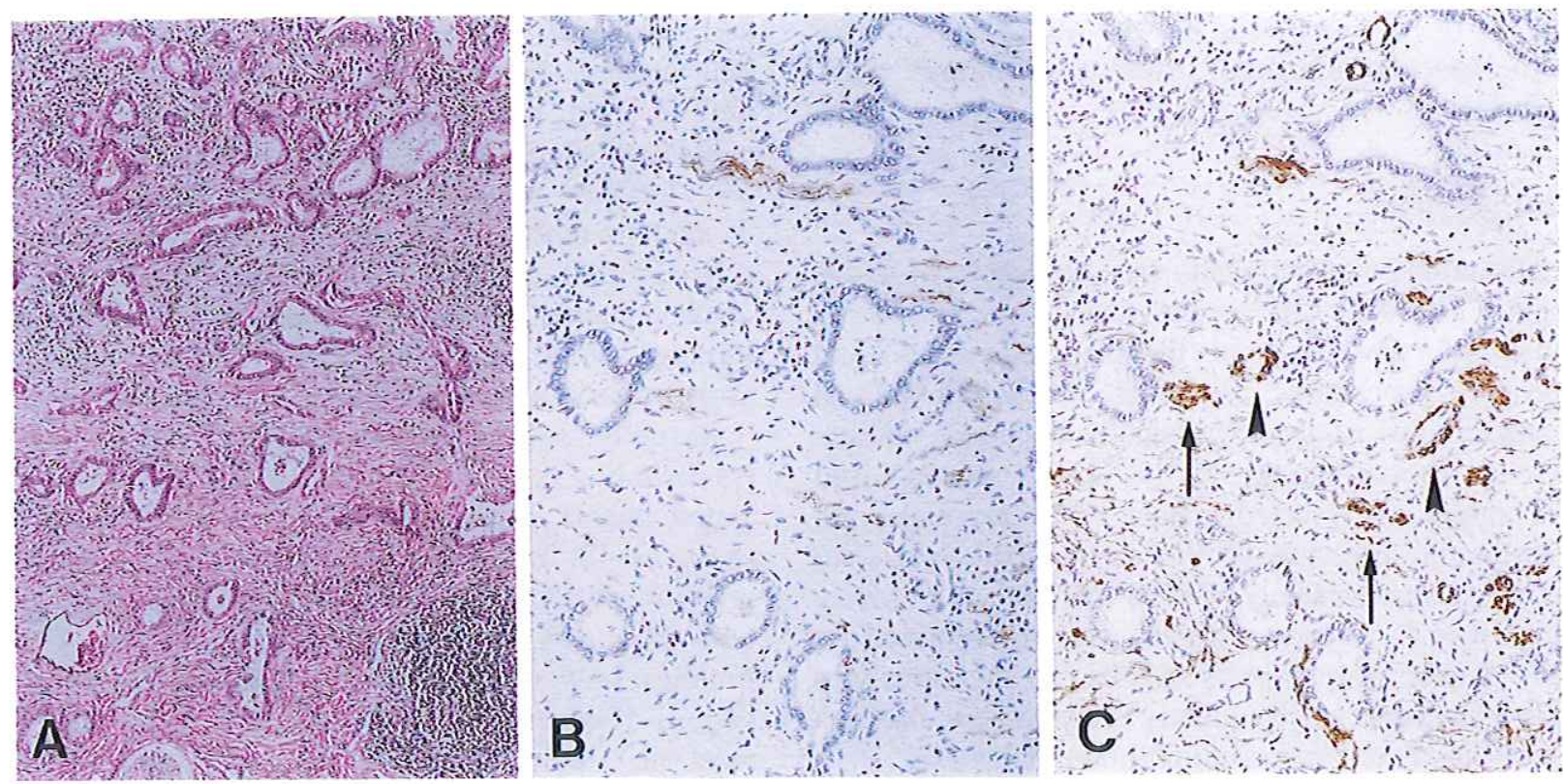

Fig. 4 Microscopic findings of extrahepatic bile duct adenocarcinoma. Adenocarcinoma cells invade the subserosal layer (A, hematoxylin and eosin, $\times 40$ ). Desmin immunoreactivity was detected at the thin fibromuscular layer (B, LSAB method, $\times$ 80). Alpha smooth muscle actin was found at the fibromuscular layer (arrows), as well as at the fibroblasts and vascular walls (arrowheads) (C, LSAB method, $\times 80$ ).

Table 2 Invasion pattern of extrahepatic bile duct cancer

\begin{tabular}{lccc}
\hline \multirow{2}{*}{ Pretreatment } & \multicolumn{3}{c}{ Stromal tumor invasion } \\
\cline { 2 - 4 } & Medullary & Intermediate & Scirrhous \\
\hline Papillary type & $19(18.6 \%)$ & $4(3.9 \%)$ & $2(2.0 \%)$ \\
Noduląr type & $4(3.9 \%)$ & $29(28.4 \%)$ & $12(11.8 \%)$ \\
Diffusely infiltrating type & $0(0 \%)$ & $1(1.0 \%)$ & $31(30.4 \%)$ \\
\hline
\end{tabular}

Table 3 Invasion and lymph node metastasis of extrahepatic bile duct cancer

\begin{tabular}{|c|c|c|c|c|c|}
\hline \multirow{2}{*}{ Depth } & \multicolumn{4}{|c|}{ Invasion factors } & \multirow{2}{*}{ Total } \\
\hline & $\operatorname{ly}(+)$ & $\mathrm{v}(+)$ & pn $(+)$ & $\mathrm{n}(+)$ & \\
\hline pTis & $0\left(\begin{array}{ll}0 \%\end{array}\right)$ & $0\left(\begin{array}{ll}0 \% \\
0\end{array}\right.$ & $0\left(\begin{array}{ll}0 & \%\end{array}\right)$ & $0\left(\begin{array}{ll}0 & \%\end{array}\right)$ & 6 \\
\hline pTl & $2(28.6 \%)$ & $0\left(\begin{array}{ll}0 \%\end{array}\right.$ & $1(14.3 \%)$ & $1(14.3 \%)$ & 7 \\
\hline pT2+pT3 & $77(86.5 \%)$ & $49(55.1 \%)$ & $78(87.6 \%)$ & $42(47.2 \%)$ & 89 \\
\hline Total & $79(77.5 \%)$ & 49 (48.0\%) & $79(77.5 \%)$ & $43(42.2 \%)$ & 102 \\
\hline
\end{tabular}

ly $(+)$, lymph vessel invasion, lyl+ to ly $3+$;

$\mathrm{v}(+)$, vascular invasion, $\mathrm{v} 1+$ to $\mathrm{v} 3+$;

pn $(+)$, perineural invasion, pn $1+$ to $\mathrm{pn} 3+$;

$\mathrm{n}(+)$, lymph node metastasis.

tastasis of extrahepatic bile duct cancer are summarized in Table 3 . None of Tis cancers (6 tumors) showed any factors of vascular/perineural invasion or lymph nodal metastasis. Only $28.6 \%(2 / 7)$ of $\mathrm{T} 1$ cancers showed vascular/perineural invasion or lymph node metastasis. Approximately $98.9 \%$ 
(88/89) of T2-3 cancers showed at least one factor of the vascular/perineural invasion and lymph nodal metastasis.

\section{DISCUSSION}

The number of surgically resected cases of extrahepatic bile duct cancers has recently increased because of advances in imaging diagnoses and operative procedures. However, the morphological characteristics of the extrahepatic bile duct cancers have not been defined. In this study, we reviewed 102 surgically resected cancer cases for clarifying growth and invasion of the extrahepatic bile duct cancer. Approximately $12.7 \%$ of the cases were pTis or pT1 cancers, which were categorized as early cancer. The majority $(87.3 \%)$ of the cases was pT2-3 cancers and frequently showed vascular/perineural invasion and/or lymph node metastasis.

In our files, most cases of extrahepatic bile duct cancers were differentiated adenocarcinomas, i.e., papillary, well differentiated or moderately differentiated tubular adenocarcinomas. The present results were similar to those reported previously $(1,21,28)$. We designated as "early cancer" cancers limited to the mucosa or invading as far as the proper muscle, i.e., pTis or $\mathrm{pT} 1$ cancers. The pTis cancers showed no vascular/perineural invasion and no lymph node metastasis. In addition, the majority (71.4\%) of pT1 cancers revealed no vascular/perineural invasion and no lymph node metastasis. The term "early cancers" was originally used in the gastric cancer field, and it was suggested to be curable by surgery (7). The Japanese Society of Biliary Surgery has proposed definition of early bile duct cancer (15). However, clinicopathological analyses of the early bile duct cancer have not yet been investigated because early cancer cases are very rare. In the present study, only limited early cancers of the extrahepatic bile duct showed vascular/perineural invasion and/or lymph node metastasis. Therefore, the definition of early cancer of extrahepatic bile duct appears suitable, similar to early gastric cancer and early gallbladder cancer. In contrast, the pT2-3 cancers, i.e., advanced cancers, very frequently exhibited vascular/ perineural invasion and/or lymph node metastasis, and were shown to be aggressive malignant tumors.

Anatomically, the extrahepatic bile duct wall has a thin fibromuscular layer (smooth muscle layer, proper muscle layer) consisting of smooth muscle bundles. Inflammation and tumor invasion occasionally destroy this thin muscle layer (11). Therefore, we used immunostaining for desmin and $\alpha-$ SMA, and evaluated invasion depth of extrahepatic bile duct cancers. Desmin was very useful for recognizing the thin fibromuscular layer, and helpful for evaluating the depth of tumor invasion $(3,23,24$, 34). $\alpha$-SMA immunoreactivity was found not only in smooth muscles, but also in the myofibroblastic cells $(22,27)$, and was less useful for evaluating the depth of tumor invasion. It is suggested that desmin staining should be performed for pathological diagnosis of early extrahepatic bile duct cancers.

Recently, several studies analyzed various markers including cell proliferation- or angiogenesis-associated factors in the extrahepatic bile duct cancers $(5,6,12-14,18,25,31,32)$. They reported that expression or alteration of the markers was correlated with prognosis or clinicopathological factors. These findings, however, have mostly been based on observations of advanced cancers, and there have been almost no studies dealing with early-stage cancers. According to our aforementioned observations, extrahepatic bile duct cancers should be subclassified into two groups, i.e., early cancers that are curable, and advanced cancers that may be poorly prognostic. Therefore, early and advanced extrahepatic bile duct cancers should be classified separately, and then analyzed.

\section{REFERENCES}

1. Albores-Saavedra J., Henson D. E. and Klimstra D. S. (1998) Tumors of the gallbladder, extrahepatic bile ducts and ampulla of Vater. In: Atlas of Tumor Pathology. Third Series Fascicle 27, pp171-210, Anmed Forces Institute of Pathology, Washington, D. C.

2. Albores-Saavedra J., Menck H. R., Scoazec J. C., Soehendra N., Wittekind C., Sriram P. V. J. and Sripa B. (2000) Carcinoma of the gallbladder and extrahepatic bile ducts. In: World Health Organization Classification of Tumours. Pathology and Genetics of Tumors of the Digestive System. (Hamilton S. R. and Aaltonen L. A., eds.), pp206-214, IARC Press, Lyon.

3. Altmannsberger M., Weber K., Droste $R$ and Osborn $M$. (1985) Desmin is a specific marker for rhabdomyosarcomas of human and rat origin. Am. J. Pathol. 118, 85-95.

4. Avrameas S. and Ternynck T. (1971) Peroxidase labelled antibody and Fab conjugates with enhanced intracellular penetration. Immunochemistry 8, 1175-1179.

5. Beazley R. M., Hadjis N., Benjamin I. S. and Blumgart L. H. (1984) Clinicopathological aspects of high bile duct cancer. Experience with resection and bypass surgical treatments. Ann. Surg. 199, 623-636.

6. Cui X., Hui A. M., Li X., Shi Y. Z., Takayama T., Hatakeyama K. and Makuuchi M. (2000) Alterations of retinoblastoma protein and p16INK4 protein expression in extrahepatic bile duct carcinomas. Hepatogastroenterology 47, 1216-1220.

7. Day D. W., Jass J. R., Price A. B., Shepherd N. A., Sloan J. M., Talbot I. C., Warren B. F. and Williams G. T. (2003) Morson and Dawson's Gastrointestinal Pathology, 4th ed., 
pp.174-177, Blackwell Publishing, Massachusetts.

8. Dowaki S., Kijima H., Kashiwagi H., Ohtani Y., Tobita K., Tsukui M., Tanaka Y., Tazawa K., Matsubayashi H., Tsuchida T., Nakamura M., Ueyama Y., Tanaka M., Tajima T. and Makuuchi H. (2000) CEA immunohistochemical localization is correlated with growth and metastasis of human gallbladder carcinoma. Int. J. Oncol. 16, 49-53.

9. Dumbar L. L., Adkins R. B, Farringer J., Waterhouse G. and O'Leary J. P. (1983) Carcinoma of the gallbladder and bile ducts: A retrospective review. Am. Surg. 49, 94-104.

10. Evander A., Fredlund P., Hoevels J., Ihse I. and Bengmark S. (1980) Evaluation of aggressive surgery for carcinoma of the extrahepatic bile ducts. Ann. Surg. 191, 23-29.

11. Frierson H. F. Jr. (1997) Gallbladder and extrahepatic biliary system. In: Histology for Pathologists, 2nd ed. (Sternberg S.S., ed.), pp 600-603, Lippincott-Raven, Philadelphia.

12. Hida Y., Morita T., Fujita M., Miyasaka Y., Horita S., Fujioka Y., Nagashima K. and Katoh H. (1999) Vascular endothelial growth factor expression is an independent negative predictor in extrahepatic biliary tract carcinomas. Anticancer Res. 19, 2257-2260.

13. Ichikawa K., Imura J., Kawamata H., Takeda J. and Fujimori T. (2002) Down-regulated pl6 expression predicts poor prognosis in patients with extrahepatic biliary tract carcinomas. Int. J. Oncol. 20, 453-461.

14. Ito Y., Takeda T., Sakon M., Monden M., Tsujimoto M. and Matsuura N. (2000) Expression and clinical significance of the G1-S modulators in carcinoma of the extrahepatic bile duct. Anticancer Res. 20, 337-344.

15. Japanese Society of Biliary Surgery. (2001) Classification of Biliary Tract Carcinoma, 1st ed., p25, Kanehara Co., Ltd., Tokyo.

16. Kashiwagi H., Kijima H., Dowaki S., Ohtani Y., Tobita K., Tsukui M., Tanaka Y., Matsubayashi H., Tsuchida T., Yamazaki H., Nakamura M., Ueyama Y., Tanaka M., Tajima T. and Makuuchi H. (2000) DF3 expression in human gallbladder carcinoma: Its significance for lymphatic invasion. Int. $J$. Oncol. 16, 455-459.

17. Kashiwagi H., Kijima H., Dowaki S., Ohtani Y., Tobita K., Yamazaki H., Nakamura M., Ueyama Y., Tanaka M., Inokuchi S. and Makuuchi H. (2001) MUC1 and MUC2 expression in human gallbladder carcinoma: A clinicopathological study and relationship with prognosis. Oncology Reports $8,485-489$.

18. Kenjo A., Abe T., Saito T., Tsuchiya T., Yamada F., Kanzaki N. and Gotoh M. (2000) Mucin ball-producing extrahepatic bile duct carcinoma. Scand. J. Gastroenterol. 35, 1330-1334.

19. Kijima H., Kashiwagi H., Dowaki S., Ohtani Y., Tobita K., Matsubayashi H., Ajioka Y., Watanabe H., Tsuchida T., Yamazaki H., Nakamura M., Ueyama Y., Tanaka M. and Makutchi H. (2000) Stromal sialyl Le expression is correlated with vascular invasion of human gallbladder adenocarcinoma. Int. J. Oncol. 17, 55-60.

20. Kijima H., Watanabe H., Iwafuchi M. and Ishihara N. (1989) Histogenesis of gallbladder carcinoma from investigation of early carcinoma and microcarcinoma. Acto Pathol. Jpn. 39, 235-244.
21. Lack E. E., Khettry U. and Legg M. A. (1990) The pancreas and extrahepatic billiary system: extrahepatic bile ducts. In: Principles and Practice of Surgical Pathology, 2nd ed. (Silverberg S. G., ed.), pp1378-1381, Churchill Livingstone, New York.

22. Lazard D., Sastre X., Frid M. G., Glukhova M. A., Thiery J. P. and Koteliansky V. E. (1993) Expression of smooth muscle-specific proteins in myoepithelium and stromal myofibroblasts of normal and malignant human breast tissue. Proc. Natl. Acad. Sci. USA 90, 999-1003.

23. Miettinen M., Lehto V. P., Ekblom P., Tasanen A. and Virtanen I. (1984) Leiomyosarcoma of the mandible: diagnosis as aided by immunohistochemical demonstration of desmin and laminin. J. Oral Pathol. 13, 373-381.

24. Mills S. E., Bova G. S., Wick M. R. and Young R. H. (1989) Leiomyosarcoma of the urinary bladder. A clinicopathologic and immunohistochemical study of 15 cases. Am. J. Sturg. Pathol. 13, 480-489.

25. Ogura Y., Takahashi K., Tabata M. and Mizumoto R. (1994) Clinicopathological study on carcinoma of the extrahepatic bile duct with special focus on cancer invasion on the surgical margins. World J. Surg. 18, 778-784.

26. Ohtani Y., Kijima H., Dowaki S., Kashiwagi H., Tobita K., Tsukui M., Tanaka Y., Tsuchida T., Tokunaga T., Yamazaki H., Nakamura M., Ueyama Y., Tanaka M., Tajima T. and Makuuchi H. (1999) Stromal expression of thrombospondin1 (TSP1) is correlated with growth and metastasis of human gallbladder carcinoma. Int. J. Oncol. 15, 453-457.

27. Ronnov-Jessen L. and Petersen O. W. (1996) A function for filamentous $\alpha$-smooth muscle actin: retardation of motility in fibroblasts. J. Cell Biol. 134, 67-80.

28. Saul S. H. (1994) Gallbladder and extrahepatic biliary tree. In: Diagnostic Surgical Pathology. (Stemberg S. S., ed.), pp1604-1607, Raven Press, New York.

29. Sobin L. H. and Wittekind C. (eds.) (1997) Extrahepatic bile duct. In: TNM Classification of Malignant Tumours, 4th ed., pp 81-83, Wiley-Liss, New York.

30. Sons H. U. and Borchard F. (1987) Carcinoma of the extrahepatic bile duct: a postmortem study of 65 cases and review of the literature. J. Surg. Oncol. 34, 6-12.

31. Sugiyama M., Atomi Y., Kuroda A. and Muto T. (1997) Bile duct carcinoma without jaundice: clues to early diagnosis. $\mathrm{He}$ patogastroenterology 44, 1477-1483.

32. Tamada S., Goto M., Nomoto M., Nagata K., Shimizu T., Tanaka S., Sakoda K., Imai K. and Yonezawa S. (2002) Expression of MUC1 and MUC2 mucins in extrahepatic bile duct carcinomas: its relationship with tumor progression and prognosis. Pathol. Int. 52, 713-723.

33. Tanaka H., Kijima H., Tokunaga T., Tajima T., Himeno S., Kenmochi T., Oshiba G., Kise Y., Nishi T., Chino O., Shimada H., Machimura T., Tanaka M. and Makuuchi H. (1999) Frequent expression of inducible nitric oxide synthase in esophageal squamous cell carcinomas. Int. J. Oncol. 14, 1069-1073.

34. Van Muijen G. N. P., Ruiter D. J. and Wamaar S. O. (1987) Coexpression of intermediate filament polypeptides in human fetal and adult tissues. Lab. Invest. 57, 359-.369. 